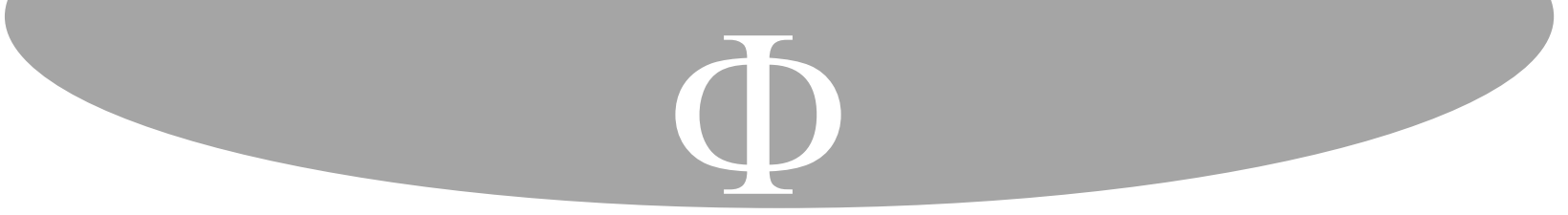

\title{
A questão primeira de Deus: O desafio humanitário da eclesiologia do século XXI*
}

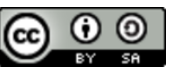

\author{
Everaldo dos Santos Mendes** \\ Clélia Peretti*** \\ Pontificia Universidade Católica do Paraná \\ Curitiba, Brasil
}

Para citar este artículo: dos Santos Mendes, Everaldo y Peretti, Clélia. «A questão primeira de Deus:

O desafio humanitário da eclesiologia do século XXI». Franciscanum 177, Vol. 64 (2022): 1-20.

\begin{abstract}
Resumo
Neste artigo, objetivamos refletir sobre a experiência cristã de Deus diante da tentação do vazio cultural que assola as «teologias» da secularização e o vazio de Deus nas «contrateologias». No percurso investigativo, revisitamos a literatura teológica da tradição católica, mapeando as contribuições das teologias da experiência cristã de Deus como a experiência de uma plenitude. Por este caminho, delineamos uma pesquisa bibliográfica de abordagem qualitativa. No seio da sociedade contemporânea, desafiada por "crises permanentes», corrupção, barbáreis e pandemia aflora a carência de um Mistério Sagrado, capaz de revelar o sentido último da existência humana. Na eclesiologia do século XXI, a experiência cristã de Deus - latino-americana e caribenha — reclama para a sua práxis histórica a epifania do rosto de um Deus sofredor. Este Deus, sensivelmente, assume o fardo da existência humana, solidarizando-se com o sofrimento de pessoas concretas, de corpo-vivente, psique e espírito - um Deus responsável, inclusivo, totalmente envolvido com o destino da humanidade e da «Casa Comum», que não renuncia a nenhuma das suas criaturas.
\end{abstract}

\footnotetext{
${ }^{*}$ Pesquisa realizada a partir de encontros realizados no Grupo de Pesquisa Teologia, Gênero e Educação TGEduc-, durante o período agosto de 2020 a fevereiro de 2021, na Pontifícia Universidade Católica do Paraná [PUCPR] em parceria com Instituto Edith Theresa Hedwing Stein - ISTEIN.

${ }^{* *}$ Doutor em Teologia pela Pontifícia Universidade Católica do Rio de Janeiro [PUC-Rio]. Pós-doutorando em Teologia da PUC-Rio. Pós-doutorando em Teologia da Pontíficia Universidade Católica do Paraná [PUCPR]. Reitor do Instituto Edith Theresa Hedwing Stein [ISTEIN]. ORCID: 0000-0002-0245-4167. Contacto: ies.istein@gmail.com

*** Doutora em Teologia pela EST; Pós-doutora em Fenomenologia pelo Centro Italiano di Ricerche Fenomenologiche e Pontifícia Universidade Lateranense; Mestre em Educação; Especialista em Educação a Distância e em Gestão de Escolas; Licenciatura em Pedagogia pela Libera Università Maria SS. Assunta; Graduada em Magistério em Ciências Religiosas pelo Pontificio Ateneo Antonianum; Bacharel em Teologia; Licenciatura em História pelo Centro Universitária Claretiano. Líder do Grupo de Pesqusa: Teologia, Gênero e Educação. Membro de International Academy of Practical Theology - IAPT - USA, da SOTER, ANTPECRE e NUPPER. Membro da Coordenação do FONAPER, na Coordenação da Educação Superior. Docente e pesquisadora no Curso do Bacharelado de Teologia e no Programa de Pós-Graduação Mestrado e Doutorado em Teologia - PPGT da PUCPR. Professor Visitante na Universidade Católica de Moçambique. Professora Visitante no Instituto Superior de Filosofia e de Teologia Dom Jaime Garcia Goulart. ORCID: https://orcid.org/0000-0003-2062-0883. Contacto: clelia.peretti@pucpr.br.
} 


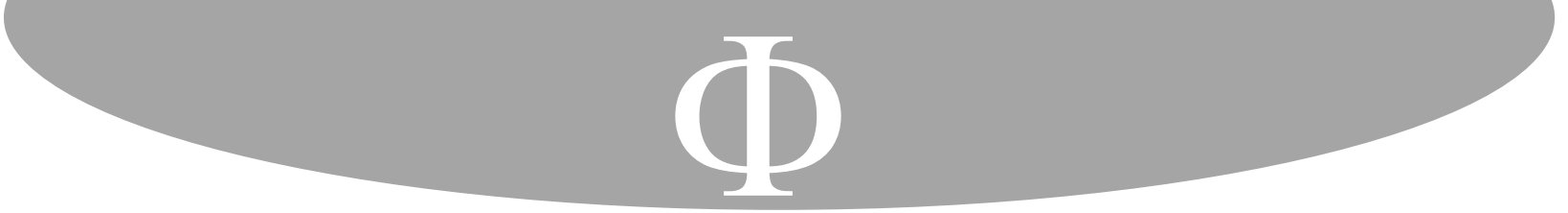

totalmente comprometido con el destino de la humanidad y de la «Casa Común», que no renuncia a ninguna de sus criaturas.

\title{
Palabras clave
}

Diseño de la modernidad, Sujeto cognoscente, Experiencia cristiana de Dios, Contrateologías, Casa común.

\section{Introdução}

\begin{abstract}
Eis que dias virão - oráculo de Iahweh — em que concluirei com a casa de Israel (e com a casa de Judá) uma aliança nova. Não como a aliança que concluí com seus pais, no dia que os tomei pela mão para fazê-los sair da terra do Egito - minha aliança que eles próprios romperam, embora eu fosse o seu Senhor, oráculo de Iahweh! Porque esta é a aliança que concluirei com a casa de Israel depois desses dias, oráculo de Iahweh. Porei minha lei no fundo de seu ser e a escreverei em seu coração. Então serei seu Deus e eles serão meu povo. Eles não terão mais que instruir seu próximo ou seu irmão, dizendo: 'Conhecei a Iahweh!' Porque todos me conhecerão, dos menores aos maiores, - oráculo de Iahweh - porque perdoarei sua culpa e não me lembrarei mais de seu pecado ${ }^{1}$.
\end{abstract}

Historicamente, diz-se que os séculos XIV e XV — estendendo-se até o século XX - são perpassados pelo crescimento da autonomia do ser humano, por grandes avanços tecnológico-científicos e pela utilização da razão para explicar o que antes competia às crenças (religiosas). No século XXI, o ser humano - e não mais Deus (como acontecia no Medievo) - passa a ser o centro do universo, dos fenômenos e dos acontecimentos. No projeto da Modernidade, o «sujeito cognoscente» passa a ser fundamento de si mesmo, tornando-se uma consciência adulta e sujeito de seu próprio acontecer histórico (devir).

Destarte, o sujeio cognoscente - emancipado - declara-se responsável por sua felicidade, que depende única e exclusivamente dele, de sua função e reflexão ${ }^{2}$. Martin Heidegger diz que o «ser humano» — Dasein (ser-aí) — abandonado por Deus esclarece por si mesmo a questão do ser, tragicamente esquecida pela metafísica tradicional — de Platão e Aristóteles até Hegel $^{3}$. Magistralmente, Maria Clara Bingemer reflete que o cristianismo histórico - religião indiscutivelmente majoritária e hegemônica no Ocidente - tropeçou em fenômenos como o teísmo, secularismo, ateísmo e agnosticismo. Nesta atmosfera de rejeição, foram atingidas - não apenas externamente, mas também enquanto estrutura de pensamento individualista - as próprias categorias mentais dos fiéis ${ }^{4}$. Por este caminho, restou ao indivíduo rejeitar o mundo moderno e refugiar-se na fé ou entrar em diálogo com o pensamento iluminista, aceitando, em suas apologias, as mesmas formas de pensamento

\footnotetext{
${ }^{1} \mathrm{Jr}$ 31, 31-34.

${ }^{2}$ Maria Clara Luccheti Bingemer, O mistério e o mundo: paixão por Deus em tempos de descrença (Rio de Janeiro: Rocco, 2013).

${ }^{3}$ Martin Heidegger, Ser y tempo. Trad. Jorge Eduardo Rivera Cruchaga (Madrid: Trotta, 2009).

${ }^{4}$ Maria Clara Lucchetto Bingemer, O mistério e o mundo: paixão por Deus em tempos de descrença.
} 


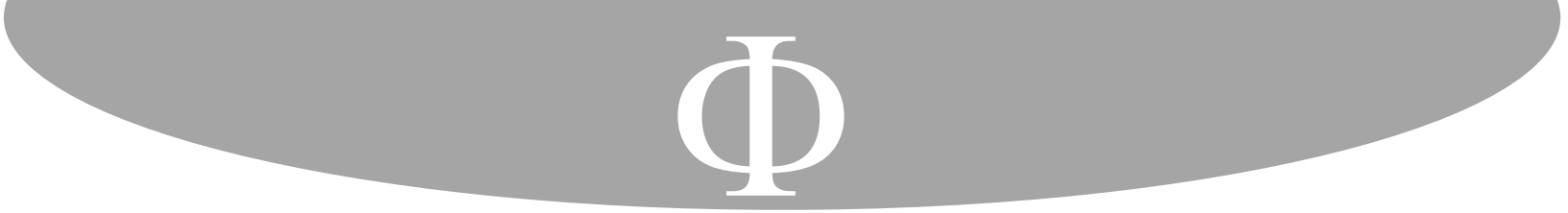

Com efeito, Deus não está oculto de nós. Deus está reservado ${ }^{12}$. No dizer de Riobaldo: «Deus é traiçoeiro! Ah, uma beleza de traiçoeiro — dá gosto! A força dele, quando quer moço! - me dá medo pavor! Deus vem vindo: ninguém não vê. Ele faz é na lei do mansinho» ${ }^{13}$.

Para Karl Barth, o que e como deveríamos ser em Cristo, e o que e como o mundo será em Cristo é o que não nos é revelado. Isto sim está oculto. Não sabemos o que dizemos quando falamos da volta de Cristo no julgamento e da ressurreição dos mortos, da vida e da morte eternas ${ }^{14}$. Mas, que tudo isso estará associado a uma revelação pungente - uma visão comparada à qual toda a nossa visão presente terá sido cegueira, exigindo de nós enxergar quando todos perderam a visão ${ }^{15}$ — é demasiado atestado nas Escrituras para que sintamos o dever de nos preparar ${ }^{16}$.

$\mathrm{Na}$ nossa caminhada pelo mundo, desconhecemos o que será revelado quando a última venda for subtraída de nossos olhos, de todos os olhos. Diante disso, como contemplaremos uns aos outros, isto é, a humanidade de hoje e a humanidade de séculos e milênios atrás, ancestrais e descendentes, maridos e esposas, sábios e tolos, opressores e oprimidos, traidores e traídos, assassinos e vítimas, Ocidente e Oriente, alemães e outros, cristãos, judeus e pagãos, ortodoxos e hereges, católicos e protestantes, luteranos e reformados? Sob que divisões e uniões, que conexões e confrontos, cruzados os lacres de todos os livros, serão abertos? Tendo em vista que muitas coisas parecerão pequenas e sem importância, que coisas parecerão grandes e importantes? Para que surpresas de todos os tipos devemos preparar-nos? Mistério é o que a natureza, como o cosmos em que vivemos e continuamos a viver aqui e agora, será para nós. Então, o que as constelações, o mar, os amplos vales e colinas que vemos e conhecemos nos dias de hoje dirão e significarão? ${ }^{17}$.

Laudato si', mi' Signore - Louvado sejas, meu Senhor, «com todas as tuas criaturas $^{18}$ louva São Francisco de Assis no "Cântico das Criaturas", evocado pelo Papa Francisco $^{19}$.

No século XXI, «falar de Deus e com Deus» ${ }^{20}$ e narrar a experiência cristã de Deus beira um anacronismo, sob o olhar de uma época que se proclama pós-teísta. Historicamente, a questão de Deus perdeu sua especificidade teológica, admitindo apenas uma formulação «honesta», articulada-se em termos etnológicos, sociológicos, psicológicos e políticos:

\footnotetext{
${ }^{12}$ Karl Barth, God Here and Now (New York: Routledge, 2003).

${ }^{13}$ João Guimarães Rosa, Grande sertão: veredas 19. ed. (Rio de Janeiro: Nova Fronteira, 2001), 39.

${ }^{14}$ Karl Barth, God Here and Now.

15 José Saramago, Ensaio sobre a cegueira. 19. ed. (São Paulo: Cia. das Letras, 2001).

${ }^{16}$ Karl Barth, God Here and Now.

${ }^{17}$ Karl Barth, God Here and Now.

${ }^{18}$ Papa Francisco, Carta Enciclica. Fratelli Tutti. Sobre a fraternidade e a amizade social. Assis, 3 de outubro de 2020 (São Paulo: Paulinas, 2020), 3.

${ }^{19}$ Papa Francisco, Carta Enciclica. Laudato si': Sobre o cuidado da casa comum. Roma, 24 de maio de 2015 (São Paulo: Paulinas, 2015).

${ }^{20}$ Carlos Josaphat, Falar de Deus e com Deus: caminhos e descaminhos das religiões hoje, 23.
} 


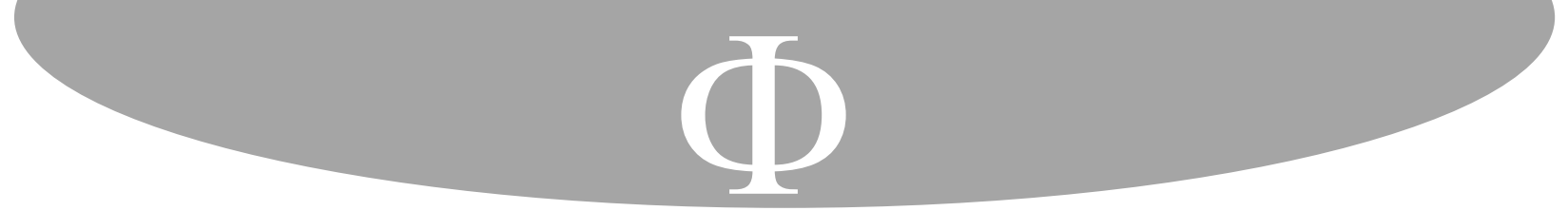

Desafio ao revedicto que parece aceito sem discussão em amplas áreas da cultura contemporânea e segundo o qual a assim chamada experiência de Deus não pode ser senão a persistência ou a sobrevivência de uma ilusão. A ilusão de Deus seria a última, entre todas as grandes ilusões que abrigaram inicialmente o homem em face de uma natureza misteriosa e hostil, que ainda resite tenazmente. Ilusão que se decompõe, no entando, e torna irrespirável o mundo da cultura moderna. Remover o cadáver de Deus, eis a empresa que tomam para si os grandes construtores da cultura pós-teísta, um Marx, um Nietzschee, um Freud ${ }^{21}$.

No século XXI, exatamente em face da tentação do vazio cultural de Deus nas teologias da secularização e o vazio espiritual de Deus expresso nas contra-teologias da sacralização, refletir sobre a experiência cristã de Deus como a vivência de uma plenitude constitui conditio sine qua non para a lucidez e o vigor da vida cristã. Trata-se de um risco que pode fazer-nos estremecer diante da gigantesca e fantástica operação da negação de Deus - dissimulada, sutil e agressiva — que invade toda nossa cultura e todas as fibras de nosso ser que nela e por ela subsiste: um risco essencial da fé que busca a inteligência. Não nos dispondo a corrê-lo, revelamos que em nós mesmos a negação de Deus terminou sua tarefa: perdemos a nossa fé em Deus, apesar de continuarmos a oferecer em espetáculo ao mundo o alarido de nossas «teologias» 22 .

Meister Eckhart, teólogo místico alemão do século XIII, escrevia:

'Saulo ergueu-se do chão. Mas, embora tivesse os olhos abertos, não via nada.' A mim me parece que essas palavrinhas têm quatro sentidos. Um sentido é: quando ele se levantou do chão, nada via com os olhos abertos, e esse nada era Deus; ver Deus ele chama, pois, de nada. O outro sentido: quando ele se levantou, não via nada a não ser Deus. O terceiro: em todas as coisas, ele não via nada a não ser Deus. O quarto: quando via Deus, via todas as coisas como sendo nada ${ }^{23}$.

É como diz Henrique C. de Lima Vaz, teólogo jesuíta: «Precisamos dizer sem equívocos que buscamos uma experiência de Deus na sua Verdade» ${ }^{24}$ «Humanamente, desprovidos da verdade experiencial de Deus, nossa vida andará errando entre muitos deuses e muitos senhores - ídolos ou imagens enganosas da Verdade que perdemos» ${ }^{25}$. Meister Eckhart diz que «Deus se derrama em todas as criaturas, e mesmo assim permanece intocado por todas elas» ${ }^{26}$.

Magristralmente, Karl Rahner reflete que o ser humano, quer o afirme expressamente ou não o afirme, quer reprima esta verdade ou a deixe aflorar à superfície, acha-se sempre

\footnotetext{
${ }^{21}$ Henrique Cláudio de Lima Vaz, «A experiência de Deus», in Frei Betto, F. et al. Experimentar Deus hoje. 2. ed. (Petrópolis, RJ: Vozes, 1976), 74.

${ }^{22}$ Henrique Cláudio de Lima Vaz, «A experiência de Deus».

${ }^{23}$ Meister Eckhart, Sobre o desprendimento e outros textos (São Paulo: Martins Fontes, 2004), Sermão 71.

${ }^{24}$ Henrique Cláudio de Lima Vaz, «A experiência de Deus», 75.

${ }^{25}$ Henrique Cláudio de Lima Vaz, «A experiência de Deus», 75.

${ }^{26}$ Mestre Eckhart, Sobre o desprendimento e outros textos, Sermão 71.
} 


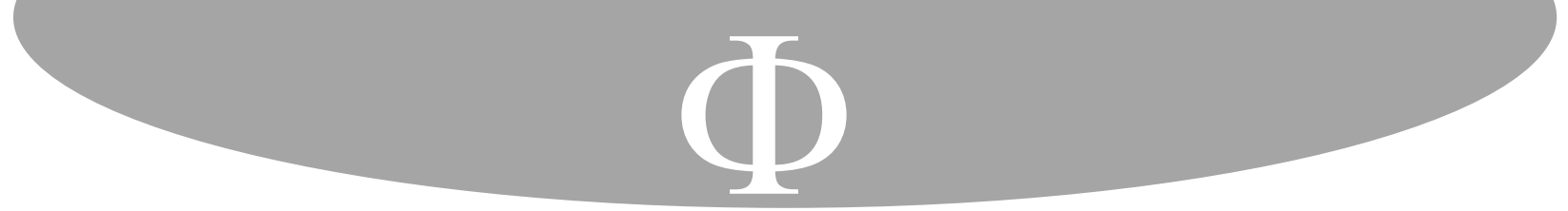

sua direita e os bodes à sua esquerda. Então dirá o Rei aos que estiverem à sua direita: 'Vinde, benditos de meu Pai, recebei por herança o Reino preparado para vós desde a fundação do mundo! Pois tive fome e me destes de comer. Tive sede e me destes de beber. Era forasteiro e me acolhestes. Estive nu e me vestistes, doente e me visitastes, preso e vistes ver-me. Então os justos lhe perguntarão: 'Senhor, quando foi que te vimos com fome e te alimentamos, com sede e te demos de beber? Quando foi que te vimos forasteiro e te recolhemos ou nú e te vestimos? Quando foi que te vimos doente ou preso e fomos te ver?' Ao que lhes disse o rei: 'Em verdade vos digo: cada vez que fizestes a um destes meus irmãos mais pequeninos, a mim o fizestes'. Em seguida, dirá aos que estiverem à sua esquerda: 'Apartai-vos de mim, malditos, para o fogo eterno preparado para o diabo e para os seus anjos. Porque tive fome e não me destes de comer. Tive sede e não me destes de beber. Fui forasteiro e não me recolhestes. Estive nu e não vestistes, doente e preso, e não me visitastes. Então também eles responderão: 'Senhor, quando é que te vimos com fome ou com sede, forasteiro ou nu, doente ou preso, e não te socorremos?' E ele responderá com estas palavras: 'Em verdade vos digo: todas as vezes que o deixastes de fazer a um desses mais pequeninos, foi a mim que o deixastes de fazer'. E irão estes para o castigo eterno enquanto os justos irão para a vida eterna ${ }^{36}$.

Partir da teologia - latino-americana da libertação — de um Deus que sofre exige de nós falar de um Deus e com um Deus envolvido na história, afetado por ela, e não é apenas um mestre transcendente que controla tudo lá do céu: a teologia do Deus que sofre diz que a história da humanidade não é apenas um teatro mas o lugar de uma luta real, a luta em que o próprio Deus - Absoluto - está envolvido e em que seu destino é decidido ${ }^{37}$.

Na Pedagogia do oprimido, Paulo Freire expressa que: «aí está a grande tarefa humanística e histórica dos oprimidos - libertar-se a si e aos opressores» ${ }^{38}$. Do ponto de vista teológico, aqueles que oprimem, exploram e violentam — em razão de seu poder não podem ter neste poder a força de libertação dos oprimidos nem de si mesmos ${ }^{39}$.

Nos últimos dolorosos dias da humanidade, assolados pela pandemia de coronavírus (COVID-19), não pode haver mais atalhos para a reflexão crítica da práxis histórica de um Deus que sofre na América Latina e no Caribe: «só o poder que nasça da liberdade dos oprimidos será suficientemente forte para libertar a ambos $»^{40}$. Por este motivo, o poder dos opressores, quando se pretende amenizar ante a debilidade dos oprimidos, não apenas quase sempre se expressa em falsa generosidade, como jamais a ultrapassa. Existencialmente, os opressores - falsamente generosos (comportamentos farisaicos) - têm necessidade, para que a sua «generosidade» continue tendo oportunidade de realizar-se, da permanência da

\footnotetext{
${ }^{36}$ Mt 25, 31-46.

${ }^{37}$ Slavoj Žižek e Boris Gunjević, O sofrimento de Deus: inversões do Apocaliipse.

${ }^{38}$ Paulo Freire, Pedagogia do oprimido. 66. ed. (Rio de Janeiro/São Paulo: Paz e Terra, 2018), 41.

${ }^{39}$ Paulo Freire, Pedagogia do oprimido.

${ }^{40}$ Paulo Freire, Pedagogia do oprimido, 41.
} 


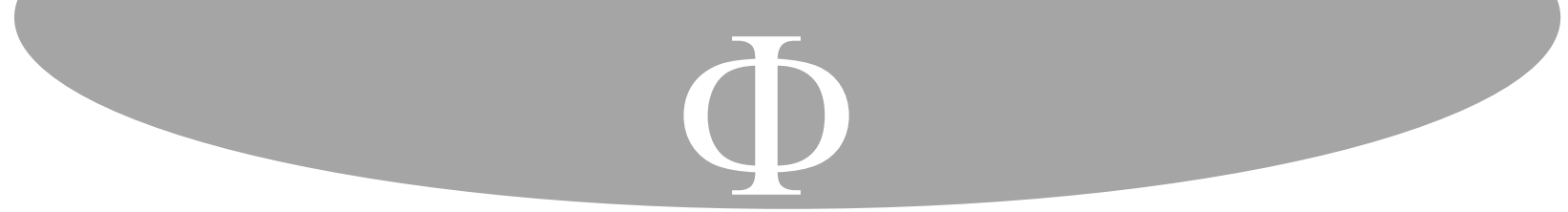

Deus desde o início da relação com o ser humano está presente conosco e em nosso meio, de modo infinitivo e isuperável em Jesus Cristo:

A mensagem de Deus é uma mensagem de esperança, uma mensagem de vida, uma mensagem que nos faz respirar aliviados e que nos dá coragem. Contudo, ela só será isso se não a tornarmos insignificante, inócuo ou até banal. O começo da sabedoria é o temor do Senhor (S1 111, 10; Pr 1, 7; 9, 10). Temor, nesse caso, não é medo, mas reverência, reverência diante de Deus enquanto sagrado, exaltado acima de tudo que puramente mundano, que justamente por isso é um fascinosum, que, no entanto, também resiste a toda injustiça, a toda violência e a toda mentira e de cada um pede contas, fazendo com que todas as máscaras caiam e todas sejam realmente iguais; é ele que, no final das contas, fará com que o direito, a verdade, a vida e o amor imperem definitivamente ${ }^{53}$.

No mundo secularizado, falta-nos experimentar Deus: uma virada teocêntrica, a partir de Jesus Cristo ${ }^{54}$. Walter Kasper diz que:

na mensagem sobre Deus não se trata de algum sentimento vago, de alguma essência suprema, de uma transcendência vaga nem de uma mistura de todos os tipos possíveis de religiões. Trata-se do Deus de Abraão, Isaac e Jacó, do Deus que apareceu para nós concretamente na face humana de Jesus Cristo e que em Jesus Cristo se tornou ser humano entre nós, seres humanos ${ }^{55}$.

Por conseguinte, escreve que:

As palavras iniciais da Constituição Eclesiástica do Concílio Vaticano II chamam a atenção para esse ponto que decide tudo; são elas: "Lumen gentium cum sit Cristo" Cristo é a luz dos povos. Não diz que a Igreja é a luz dos povos, não é ela que está no centro, não é ela que deve querer brilhar, é Cristo que deve vir a brilhar e reluzir por meio dela. A Igreja é como a luz, que só reflete a luz que recebe do sol que é Cristo. Por isso, a Igreja só poderá ter futuro se refletir Jesus Cristo e sua mensagem do Reino de Deus vindouro ${ }^{56}$.

Do ponto de vista da teologia latino-americana, Jesus é um novum, que extrapola os nossos parâmetros e liberta-nos da ditadura daquele que determina o espírito de nossa época, tido como politicamente correto ${ }^{57}$.

Vendo ele as multidões, subiu à montanha. Ao sentar-se, aproximaram-se dele os seus discípulos. E pôs-se a falar e os ensinava, dizendo:

'Felizes os pobres de espírito, porque deles é o Reino dos Céus.

Felizes os mansos

porque herdarão a terra.

\footnotetext{
${ }^{53}$ Walter Kasper, A Igreja Católica: essência, realidade e missão.

${ }^{54}$ Walter Kasper, A Igreja Católica: essência, realidade e missão.

${ }^{55}$ Walter Kasper, A Igreja Católica: essência, realidade e missão, 420.

${ }^{56}$ Walter Kasper, A Igreja Católica: essência, realidade e missão, 421.

${ }^{57}$ Walter Kasper, A Igreja Católica: essência, realidade e missão, 419.
} 


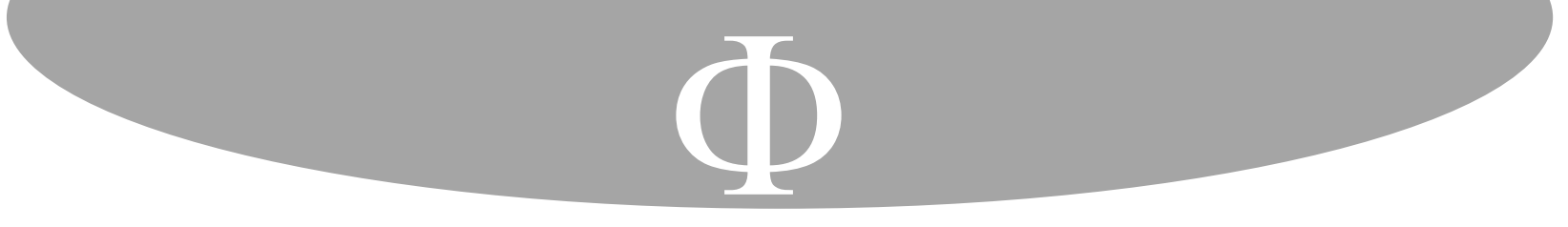

Teologicamente, com a origem trinitária e a estruturação à imagem da Trindade, «povo de Deus» e «comunhão», o Concílio Vaticano II redescobre a destinação Trinitária da Igreja e sua índole escatológica: o povo peregrino rumo à glória da Jerusalém celeste, cuja imagem e antecipação é a figura de Maria. Não é indiscutível que a índole escatológica evidencia a provisoriedade de todas as realizações eclesiais: a Igreja ainda não se constituiu de todo, ao contrário, é - de modo constitutivo - pobre e serva, semper reformanda et purificanda. Ela não se identifica com o Reino, é dele apenas a forma inicial. Por esta via, a meio caminho entre o dom já recebido e a promessa ainda não cumprida, a Igreja cresce em direção à manifestação final do Reino de Deus, auxiliada na peregrinação temporal pela comunhão com a Igreja celeste ${ }^{75}$.

No dizer de Bruno Forte, «a Igreja não nasce "de baixo", isto é, de uma exigência de sociabilidade amadurecida na história: a Igreja vem "do alto" e é a realização, já iniciada e ainda não acabada, do plano divino da aventura humana ${ }^{76}$. Historicamente, a comunhão eclesial constitui-se na unidade e diversidade dos carismas e ministérios. Para o autor, Trindade não é só a fonte dessa realidade, como também é o seu cume. Por meio da Trindade, o dinamismo da Igreja é impulsionado para uma abertura ao futuro escatológico que ela já experimenta, mas ainda não totalmente. Nesse itinerário, Maria desvela-se Mãe e Modelo ícone da Igreja ${ }^{77}$.

Magistralmente, Bruno Forte reflete sobre a união entre a Igreja militante, padecente e triunfante, que futuramente encontrar-se-ã0 no seio Trinitário. Nesta tensão entre o já e o ainda não, situa-se a realidade do pecado na Igreja que não a mancha, pois ela é indefectivelmente santa, mas necessita de contínua purificação. A partir dessa constatação, o caminho de «união» com a Trindade passa a ser compreendido mais amplamente, considerando também aqueles que não fazem parte da perfeita comunhão da Igreja. Na realidade militante, todas essas coisas são consideradas, rezadas e trabalhadas na tensão escatológica final, na esperança da suprema e perfeita união de tudo na Trindade. Ela é que é a fonte, a ordem e o fim da Igreja - a Igreja é ícone da Trindade ${ }^{78}$.

$\mathrm{Na}$ tentativa de superar a identificação visibilista entre a Igreja Corpo de Cristo e a Igreja Católica Romana, o Concílio Vaticano II afirma que a única Igreja de Cristo que no Símbolo confessamos una, santa, católica e apostólica subsiste na Igreja Católica. Historicamente, o subsistit corrige o et do texto original, reconhecendo a plenitude da realidade eclesial na Igreja Católica, sem excluir a possibilidade de realização da plenitude em outras igrejas cristãs. Funda-se aqui a doutrina conciliar de "graus de comunhão" que, abandonando a lógica do «tudo ou nada»; a Igreja Católica é a Igreja, as outras comunidades cristãs não o são; reconhece a efetivação do mistério eclesial em vários graus nas várias

\footnotetext{
${ }^{75}$ Bruno Forte, A Igreja ícone da Trindade: breve eclesiologia.

${ }^{76}$ Bruno Forte, Nos caminhos do Uno: metafísica e teologia. Trad. Antonio Efro Feltrin (São Paulo: Paulinas, 2005).

${ }^{77}$ Bruno Forte, A Igreja ícone da Trindade: breve eclesiologia.

${ }^{78}$ Bruno Forte, A Igreja ícone da Trindade: breve eclesiologia.
} 


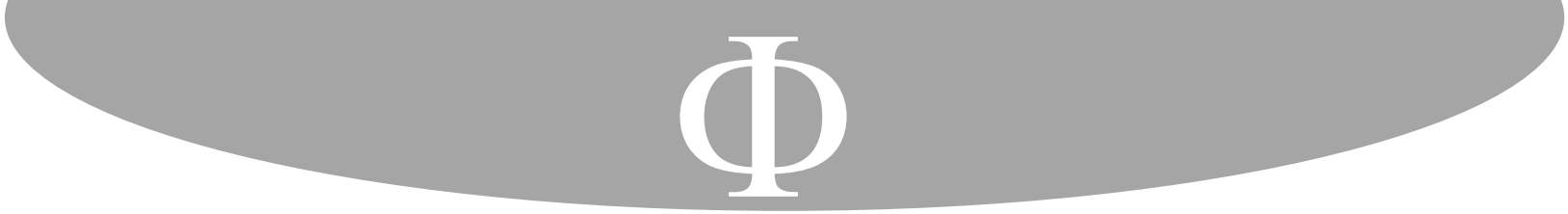

comunhões cristãs, de acordo com os elementos de eclesialidade: Palavra de Deus, sacramentos, ministério ordenado etc. presentes nelas ${ }^{79}$.

\section{Bibliografía}

Barth, Karl. God Here and Now. New York: Routledge, 2003.

Benário, Olga. «Esta é a minha despedida: de Olga Benário para Luís Carlos Prestes e Anita Leocadia». Abr. 1942. In Rodrigues, Sérgio Org. Cartas brasileiras: correspondências históricas, políticas, célebres, hilárias e inesquecíveis que marcaram o país. São Paulo: Companhia das Letras, 2017.

Bíblia. Bíblia de Jerusalém. São Paulo: Paulus, 2002.

Bingemer, Maria Clara Luccheti. O mistério e o mundo: paixão por Deus em tempos de descrença. Rio de Janeiro: Rocco, 2013.

Castiñeira, Angel A experiênciade Deus na pós-modernidade. Petrópolis, RJ: Vozes, 1997.

Comblin, José. O povo de Deus. São Paulo: Paulus, 2002.

Eckhart, Meister. Sobre o desprendimento e outros textos. São Paulo: Martins Fontes, 2004. Forte, Bruno. A Igreja Ícone da Trindade: breve eclesiologia. São Paulo: Loyola, 1987.

Forte, Bruno. Nos caminhos do Uno: metafísica e teologia. Tradução Antonio Efro Feltrin. São Paulo: Paulinas, 2005.

Francisco, Papa. Carta Enciclica. Fratelli Tutti. Sobre a fraternidade e a amizade social. Assis, 3 de outubro de 2020. São Paulo: Paulinas, 2020.

Francisco, Papa. Carta Encíclica. Laudato si': Sobre o cuidado da casa comum. Roma, 24 de maio de 2015. São Paulo: Paulinas, 2015.

Freire, Paulo. Pedagogia do oprimido. 66. ed. Rio de Janeiro/São Paulo: Paz e Terra, 2018. Heidegger, Martin. Ser y tempo. Tradução Jorge Eduardo Rivera Cruchaga. Madrid: Trotta, 2009.

Jesus, Carolina Maria de. Quarto de despejo: diário de uma favelada. 10. ed. São Paulo: Ática, 2014.

Josaphat, Carlos. Falar de Deus e com Deus: caminhos e descaminhos das religiões hoje. São Paulo: Paulus, 2004.

Kager, Richard. Die Theologische Hermeneutik Johann Adam Möhlers, (1796-1838). Dissertation zur Erlangung des Doktortitels an der Theologischen Fakultät der Universität Freiburg Schweiz, Freiburg Schweiz, November 2004.

Kasper, Walter. A Igreja Católica: essência, realidade e missão. Tradução Nélio Schneider. São Leopoldo, RS: Unisinos, 2012.

Lima Vaz, Henrique Cláudio de. «A experiência de Deus». In Frei Betto, et al. Experimentar Deus hoje. 2. ed. Petrópolis, RJ: Vozes, 1976.

Mendes, Everaldo Santos; Morais, Rossival Sampaio. A arte de educar em Carolina Maria de Jesus. In: Mendes, Everaldo Santos; Santos, Adevanucia Nere; Fernandes, Stela Santos (orgs.). Educação, diversidades e inclusão: travessias pedagógicas e sociais em tempos de pandemia. Curitiba: Bagai, 2020.

\footnotetext{
${ }^{79}$ Bruno Forte, A Igreja ícone da Trindade: breve eclesiologia.
} 


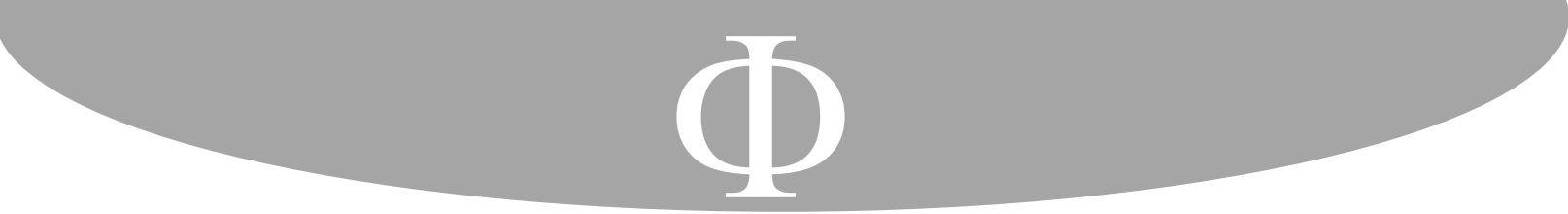

Nietzsche, Wilhelm Friedrich. Assim falava Zaratustra. S/l: Hemus, 2002.

Rahner, Karl. Curso fundamental da fé: introdução ao conceito de cristianismo. Trad. Alberto Costa. 4. ed. São Paulo: Paulus, 2008.

Rilke, Rainer Maria. O livro de horas. Tradução Geir Campos. Rio de Janeiro: Civilização Brasileira, 1993.

Rosa, Guimarães J., Grande sertão: veredas. 19. ed. Rio de Janeiro: Nova Fronteira, 2001.

Saramago, José. Ensaio sobre a cegueira. 19. ed. São Paulo: Cia. das Letras, 2001.

Stein, Edith. «Ser Finito y Ser Eterno: ensayo de una ascensiónal sentido del ser». In Stein, Edith. Obras Completas, III: Escritos Filosóficos. Etapa de pensamiento cristiano: 1921-1936. Tradução Alberto Pérez, OCD; José Mardomingo; Constantino Ruiz Garrido. vol. 3. Vitoria: El Carmen; Madrid: Espiritualidad; Burgos: Monte Carmelo, 2007.

Tagore, Rabindranath. Poesiamística: lírica breve. São Paulo: Paulus, 2003.

Tutu, Desmond. Deus não é cristão e outras provocações. Trad. Lilian Jenkino. Rio de Janeiro: Thomas Nelson Brasil, 2012.

Žižek Slavoj; Gunjević, Boris. O sofrimento de Deus: inversões do Apocalipse. Tradução Rogério Bettoni. Belo Horizonte: Autêntica, 2015.

Enviado: 19 de febrero de 2021 Aceptado: 2 de mayo de 2021 